\title{
BMJ Open Using frailty and quality of life measures in clinical care of the elderly in Canada to predict death, nursing home transfer and hospitalisation - the frailty and ageing cohort study
}

Ted Rosenberg (1), ${ }^{1}$ Patrick Montgomery, ${ }^{2}$ Vikki Hay, ${ }^{3}$ Rory Lattimer ${ }^{3}$

To cite: Rosenberg T, Montgomery P, Hay V, et al. Using frailty and quality of life measures in clinical care of the elderly in Canada to predict death, nursing home transfer and hospitalisation - the frailty and ageing cohort study. BMJ Open 2019;9:e032712. doi:10.1136/ bmjopen-2019-032712

- Prepublication history and additional material for this paper are available online. To view these files, please visit the journal online (http://dx.doi. org/10.1136/bmjopen-2019032712).

Received 02 July 2019 Revised 07 October 2019 Accepted 18 0ctober 2019

\section{Check for updates}

(C) Author(s) (or their employer(s)) 2019. Re-use permitted under CC BY-NC. No commercial re-use. See rights and permissions. Published by BMJ.

${ }^{1}$ Family Practice, The University of British Columbia Faculty of Medicine, Victoria, British Columbia, Canada

${ }^{2}$ Geriatriac Medicine (Retired), The University of British Columbia Faculty of Medicine, Victoria, British Columbia,

Canada

${ }^{3}$ Home Team Medical Services, Victoria, British Columbia, Canada

\section{Correspondence to} Dr Ted Rosenberg; trosenberg@hometeammedical. ca

\section{ABSTRACT}

Objective To assess the value of using frailty measures in primary care for predicting death, nursing home transfer (NHT) and hospital admission.

Design Cohort study.

Setting and participants All 380 people, mean age 88.4, living in the community and receiving home-based primary geriatric care from one practice in Victoria, Canada. Interventions/measurements A 60 min baseline assessment which included: Clinical Frailty Scale (CFS), EuroQol EQ-5D-5L (EQ-5D), EuroQol Visual Analogue Scale (EQ-VAS) and Gait Speed (Gaitspeed).

Outcomes Death, NHT and hospital admission. Results During 18 months of follow-up, there were $39(10.3 \%)$ deaths, 48 (12.6\%) NHTs and $93(24.5 \%)$ individuals admitted to hospital. All three outcomes were predicted by: CFS Level $6+7 / 4+5$ (HR death 5.92 , $95 \% \mathrm{Cl} 3.12$ to 11.22 , NHT $6.00,95 \% \mathrm{Cl} 3.37$ to 10.66 and hospital admission $2.92,95 \% \mathrm{Cl} 1.93$ to 4.40 ); EQ-5D Quintile 1/Quintile 5 (death $6.26,95 \% \mathrm{Cl} 2.11$ to 18.62 ; NHT $3.18,95 \% \mathrm{Cl} 1.29$ to 7.82 and hospital admission 2.94, 95\% Cl 1.47 to 5.87); EQ-VAS Q1/Q5 (death 7.0, $95 \% \mathrm{Cl} 2.34$ to 20.93 ; NHT $3.38,95 \% \mathrm{Cl} 1.22$ to 9.35 and hospital admission $6.69,95 \% \mathrm{Cl} 3.20$ to 13.99 ) and Gaitspeed (death 5.87, 95\% Cl 1.78 to 19.34; NHT 8.51, $95 \% \mathrm{Cl} 3.18$ to 22.79 and hospital admission 11.05 , $95 \% \mathrm{Cl} 5.45$ to 22.40 ). Medical diagnoses, multiple comorbidities and polypharmacy were weaker predictors of these outcomes. Cox regression analyses showed CFS (adjusted HR 2.88, 95\% Cl 1.23 to 6.68), EQ-VAS (0.96, $95 \% \mathrm{Cl} 0.93$ to 0.98 ), estimated glomerular filtration rate $(0.97,95 \% \mathrm{Cl} 0.95$ to 1.00$)$ and haemoglobin $(0.97,95 \% \mathrm{Cl}$ 0.94 to 0.99 ) were independently associated with death. Gaitspeed $(0.13,95 \% \mathrm{Cl} 0.03$ to 0.57$)$, Geriatric Depression Scale $(1.39,95 \% \mathrm{Cl} 1.07$ to 1.82$)$ and dementia diagnosis $(4.61,95 \% \mathrm{Cl} 1.86$ to 11.44$)$ were associated with NHT. Only CFS $(1.75,95 \% \mathrm{Cl} 1.21$ to 2.51$)$ and EQ-VAS (0.98, $95 \% \mathrm{Cl} 0.96$ to 0.99 ) were associated with hospital admission. No other diagnoses, polypharmacy nor multiple comorbidities predicted these outcomes.

Conclusions For elderly people, standardised simple measures of frailty and health status were stronger predictors of death, NHT and hospital admission than medical diagnoses. Consideration should be given to adding these measures into usual medical care for this age group.
Strengths and limitations of this study

- The Frailty and Ageing Cohort Study (FACTS) is a pragmatic study that embedded valid, reliable and responsive measures of health status and frailty into usual care for a community based elderly population to determine risk for death, nursing home transfer and hospital admission and for planning and evaluation.

- The baseline assessment was found valuable by patients and caregivers and can be administered in $<60$ min by a trained member of an interdisciplinary team.

- We had a high response rate and $100 \%$ follow-up of important longitudinal outcomes.

- Baseline measurement was performed by nurses involved in patient care, but outcomes were objective and measured independently.

- These findings may not be generalisable to a nonfrail elderly population or people living in nursing homes.

\section{INTRODUCTION}

The elderly population are the highest users of hospital ${ }^{1}$ and nursing home care ${ }^{2}$ for all adult age groups. However, they are not a homogeneous population with some being frail. Two main models of frailty have been described. ${ }^{3}$ The Frailty Phenotype model has been characterised by unintentional weight loss, reduced muscle mass and strength, reduced gait speed, fatigue and low energy expenditure. The second model of frailty is the Cumulative Deficit model which characterises frailty as a cumulation of deficits caused by diseases, injuries and ageing. Both models describe a frailty syndrome characterised by loss of homeostatic reserve and increased vulnerability to adverse outcomes after seemingly minor illnesses, injuries or changes in medication. The frail elderly group are at highest risk for death ${ }^{4}$ as well as 
a variety of conditions that may compromise their quality of life, ${ }^{5}$ lead to hospital admission (HA),${ }^{6}$ loss of independence $^{7}$ and nursing home transfer (NHT) ${ }^{8}$ The prevalence of frailty is estimated to be $14 \%$ for ages $>65,30 \%$ for ages 80 to 90 and up to $50 \%$ for ages $>90 .{ }^{49-12}$ Despite the increasing burden of frailty in ageing populations, there has been difficulty targeting this group in primary care. ${ }^{12}{ }^{13}$ It can be challenging to objectively distinguish the frail group from well elderly people and quantify their level of risk. Despite the availability of several well validated tools, ${ }^{14-16}$ few measures of frailty are used in routine medical care. ${ }^{12}$ The health risks for this population are usually poorly estimated from the presence and severity of chronic medical diagnoses alone. ${ }^{17} 18$

The Frailty and Ageing Cohort Study (FACTS) was initiated to improve medical care for the elderly by introducing valid, reliable and responsive frailty and health status measures into usual primary care. We hypothesised that in addition to improving care, these health status measures would be better predictors of death, NHT and HA than medical diagnoses. We chose measures that would be: (1) easy to administer, (2) clinically useful for individual patient care and (3) useful for evaluating interventions at a programme level. A pilot study approved by the University of British Columbia was done in 2015 with 57 elderly people living in the community. We tested a battery of physical, mental and quality of life measures selected from the literature. We found that: (1) the assessment could be done in under $60 \mathrm{~min}$ by a trained nurse, (2) the shorter 3-metre gait speed test was as precise, valid and reliable in a home setting compared with the 4-metre test $^{19}$ and (3) testing was acceptable to elderly people with $89 \%$ reporting it relevant to their health and that they would be prepared to repeat it.

In May 2017 we began administering the FACTS assessment to all the people in our primary-care geriatric practice. This study reports on predictors of death, NHT and hospitalisation after the first 18 months of follow-up.

\section{METHODS}

\section{Setting/participants}

We included all 380 elderly people, living in the community and receiving home-based primary care from one interdisciplinary geriatric medical practice in Victoria, Canada, between 1 May, 2017, and 30 October, 2018. The description of this practice and outcomes from this model of care have previously been reported ${ }^{20}$ Eligibility criteria to enter this practice include: (1) age $\geq 70$, (2) difficulty accessing office-based care, (3) presence of a frailty syndrome (eg, dementia, falls and chronic pain) and/or (4) multiple comorbidities and need for complex interdisciplinary medical care.

\section{Measurements}

Our practice nurses performed the FACTS assessments in people's homes. This assessment included:
Frailty and health status measures

General frailty was measured with the Clinical Frailty Scale $(\mathrm{CFS})^{14}$ using the following criteria for levels: Level $\leq 3$ - well+/-asymptomatic chronic disease, Level 4 chronic symptoms or slowed down, Level 5 - dependent in any instrumental activity of daily living (IADL), Level 6 - dependent in at least one basic activity of daily living (BADL) or requiring assistance with stairs and Level 7 complete dependency in IADL and BADL. The EuroQol EQ-5D-5L Summary Index (EQ-5D) (https://euroqol. org/), administered by interview, was used to measure health-related quality of life (HRQoL) using Canadian norms. ${ }^{21}$ The EQ-5D uses a time-trade-off method to establish population norms about how people value their health. Scores range from negative 0.148 (health state worse than death) to 0.949 (their best possible health state). The EuroQol 100-point vertical Visual Analogue Scale (EQ-VAS) was used to measure self-reported health. It is rated from 0 - 'The worst health you can imagine' to 100 - 'the best health you can imagine'.

Cognitive impairment was measured with the Montreal Cognitive Assessment (MoCA) (https://www.mocatest. org/). Depression was assessed with the 5-point Geriatric Depression Scale (GDS) ${ }^{22-24}$ The Mini-Nutritional Assessment Short Form (MNA-SF), ${ }^{1825-28}$ Nestlé (https:// www.mna-elderly.com/) was used to assess nutritional risk. Because of the high prevalence of oedema, only body mass index and not calf circumference was used for the MNA-SF. The 3-metre gait speed ${ }^{29-31}$ (Gaitspeed) was performed with people's usual walking aid and asking them to walk at a comfortable pace. Gaitspeed was measured from the average of the second and third tests and reported in metres/second $(\mathrm{m} / \mathrm{s})$. Grip strength $^{10}{ }^{32-34}$ (Gripstrength) in $\mathrm{kg}$ was measured with a Jamar Dynamometer using the dominant or stronger hand with the patient sitting with their feet on the floor. The average of three trials was used. The 3-oz water swallow test ${ }^{35-41}$ (WST) was used to assess dysphagia and risk for aspiration. Failure was either: inability to drink it all without stopping, coughing while drinking or a wet voice when finished. Sitting and standing blood pressure (BP) were measured with a sphygmomanometer and the difference was recorded. Electronic forms were created for all the tests for use with our OSCAR electronic medical record (EMR) - https://oscar-emr.com/. The EQ-VAS was tested with a marker on a laminated sheet and MoCA trail-making, cube and clock test were done on paper and scanned into the chart. All questionnaires were done by interview.

Demographics, medications, laboratory values, medical diagnoses Demographics, medications, laboratory values and medical diagnoses were abstracted from the EMR. The medical diagnoses were manually audited and abstracted from a medical history text box that is part of the EMR. The drugs and laboratory values are entered into the database as discrete variables and were queried from the database using the subjects' unique personal identifiers. 
Drugs included: all prescription drugs, prescription eye drops, daily acetaminophen or non-steroidal antiinflammatory drug and prescription vitamins (eg, folic acid or vitamin B12). We did not include calcium, vitamin $\mathrm{D}$, laxatives or other over-the-counter drugs, vitamins or supplements. The list of diagnoses in the EMR were used to classify serious symptomatic medical conditions: (1) Neurological - any of Parkinsonism, neurodegenerative diseases (excluding dementia from this category), stroke/transient ischaemic attack and peripheral neuropathy; (2) Respiratory - any of chronic obstructive pulmonary disease/asthma, interstitial lung disease, pulmonary embolus with chronic dyspnoea; (3) Cardiac - any of ischaemic heart disease, congestive heart failure, atrial fibrillation/flutter, pacemaker, valvular heart disease; (4) Hypertension on treatment; (5) Osteoporotic fracture of either hip, vertebra, forearm, humerus or ribs; (6) Cancer - active excluding non-melanoma skin malignancy; (7) Osteoarthritis or other chronic pain syndrome on regular analgesia; (8) Dementia - Diagnostic and Statistical Manual of Mental Disorders, Fourth Edition criteria and (9) Mood Disorder - including either depression, bipolar disorder or chronic generalised anxiety on medication. Laboratory tests included: estimated glomerular filtration rate (eGFR) in $\mathrm{mL} / \mathrm{min} / 1.73 \mathrm{~m}^{2}$, haemoglobin $(\mathrm{Hgb})$ in $\mathrm{g} / \mathrm{dL}$ and haemoglobin Alc (HgbAlc) in $\%$. Multiple comorbidities ${ }^{42}$ was defined as having three or more of the listed disease systems previously described and including Stages 3B to 5 chronic kidney disease or diabetes (HgbAlc >6.9). We took a $10 \%$ random sample of all the charts to examine the reliability of the initial audit of the medical history. The second auditor (PM), who was not involved in patient care, was blinded to the results from the main audit that was used for the data analyses (TR). There was a $2.3 \%$ discrepancy between the two auditors.

\section{Outcomes}

All charts were audited by electronic query of the EMR for dates of discharge from the practice, death and NHT. NHTs in Canada are permanent moves for frail people requiring long-term residential complex care. All the charts for people in the study were manually reviewed for accuracy of discharge status and dates of discharge. There is one electronic hospital record for the greater Victoria area which was manually audited for hospital admissions. The number of persons with any admission over the time period was recorded. The nurses who did the assessment were not involved in collecting data on outcomes. The auditors (TR and RL) could access the results of the frailty assessments. However, the outcomes were categorical and the result of a query form the EMR.

\section{Statistics}

Means and SD were measured and medians were used if data was not normally distributed. Two-sided t-tests were used for continuous data and $\mathrm{X}^{2}$ tests with Yates correction for categorical data. Fisher exact test was used if there were less than six observations in one cell.

Data was censored for the duration of observation. Continuous variables were broken into quintiles to calculate HRs for death, NHT and HA. Quintile 1 (Q1) and Quintile 5 (Q5) were compared for HRs, except for Gripstrength which was broken into quartiles because of the smaller numbers for each sex. Kaplan-Meier curves and HRs with $95 \%$ CI were tested with the log-rank test for statistical significance.

Cox proportional hazards stepwise regression was used for multivariate analysis. The CFS was strongly associated with each outcome, so other variables that were significant on univariate analysis were added to a two-variable model with CFS. Each of the variables that were significant in the two-variable model were then added into an overall model. All the frailty test measures, age, number of drugs, eGFR and Hgb were entered as continuous variables and WST, diagnostic categories and sex were entered as categorical variables. The final models were adjusted for age, sex, presence of multiple comorbidities and number of drugs. Statistical significance for $p$ values was set at $<0.05$. Subjects with incomplete data were included in the analyses. Statistical analyses were done with Number Cruncher Statistical System V.10.

An average of $14.1 \%$ of people declined to have all or part of the FACTS assessment done (table 1). We had $100 \%$ assessment for the three main outcomes as well CFS scores. Because there was minor variability in response rates to individual questionnaires, we coded subjects as non-respondents if they were missing the EQ-5D score. There were 53 (13.9\%) non-respondents and $327(86.1 \%)$ with complete data. Online supplementary table 1 compares respondents to non-respondents for key baseline characteristics and outcomes to estimate the effect of response bias. To further test for responserate bias, missing data was mapped to the CFS score and the average EQ-5D and Gaitspeed Quintiles for each CFS level was imputed for the missing data (online supplementary table 2).

\section{Patient and public involvement}

There were no patients involved in the planning and development of the research study. Patients participating in the pilot study were surveyed about the burden and relevance of the FACTS assessment. All patients in the practice were sent a summary of the pilot study results in 2016. Patients and caregivers are advised of the results of their personal FACTS assessment as part of care-planning.

\section{RESULTS}

All 380 people in the practice between 1 May, 2017, and 31 October, 2019, were included in the analysis. Table 1 shows the test administration rates, demographics and health status measures for the population. The average test administration rate was $85.9 \%$ (range: $80 \%$ to $100 \%$ ) for the nine main health status measures. The mean 


\begin{tabular}{|c|c|c|}
\hline Variable & Results & $\begin{array}{l}\text { No. }(\%) \\
\text { tested }\end{array}$ \\
\hline Age mean (SD) & $88.4(6.5)$ & $380(100)$ \\
\hline Female No. (\%) & $275(72.4)$ & $380(100)$ \\
\hline Marital status No. (\%) & & 372 (97.9) \\
\hline Widowed & $221(59.4)$ & \\
\hline Married & $108(29)$ & \\
\hline Divorced & $31(3.2)$ & \\
\hline Never married & $12(3.2)$ & \\
\hline Housing No. (\%) & & $372(97.9)$ \\
\hline House/apartment & $219(58.8)$ & \\
\hline Retirement home & $110(29.6)$ & \\
\hline Assisted living & $43(11.6)$ & \\
\hline Clinical frailty scale mean (SD) & $5.6(0.8)$ & $380(100)$ \\
\hline$<4$ No. $(\%)$ & $5(1.3)$ & \\
\hline 4 No. (\%) & $33(8.7)$ & \\
\hline 5 No. (\%) & $112(29.5)$ & \\
\hline 6 No. (\%) & $192(50.5)$ & \\
\hline 7 No. (\%) & $38(10)$ & \\
\hline EuroQol EQ-5D-5L mean (SD) & $0.72(0.18)$ & $327(86.1)$ \\
\hline $\begin{array}{l}\text { EuroQol visual analogue scale } \\
\text { mean (SD) }\end{array}$ & $71.5(18.7)$ & $321(84.5)$ \\
\hline $\begin{array}{l}\text { Montreal cognitive assessment } \\
\text { mean (SD) }\end{array}$ & $20.6(6.4)$ & $321(84.5)$ \\
\hline $\begin{array}{l}\text { 5-point geriatric depression } \\
\text { scale mean (SD) }\end{array}$ & $1.3(1.3)$ & 329 (86.6) \\
\hline Gait speed metres/second & $0.59(0.30)$ & $326(85.8)$ \\
\hline
\end{tabular}
mean (SD)

\begin{tabular}{|c|c|c|}
\hline $\begin{array}{l}\text { Grip strength kg. mean (SD) - } \\
\text { males }\end{array}$ & $23.2(9.0)$ & $84(80.0)$ \\
\hline $\begin{array}{l}\text { Grip strength kg. mean (SD) - } \\
\text { females }\end{array}$ & $13.6(16.6)$ & $231(84.0)$ \\
\hline $\begin{array}{l}\text { Water swallow test - failed No. } \\
(\%)\end{array}$ & $67(21.8)$ & $307(80.8)$ \\
\hline $\begin{array}{l}\text { Mini-nutritional assessment } \\
\text { short form mean (SD) }\end{array}$ & $11.8(2.1)$ & $308(81.1)$ \\
\hline Systolic BP mm hg mean (SD) & $134.6(15.9)$ & $324(85.3)$ \\
\hline Diastolic BP mm hg mean (SD) & $68.7(8.8)$ & $324(85.3)$ \\
\hline $\begin{array}{l}\text { Orthostatic drop SBP }>20 \mathrm{~mm} \\
\text { hg - sit to stand } \\
\text { No. }(\%)\end{array}$ & $22(7.1)$ & $308(81.1)$ \\
\hline Haemoglobin <110 No. (\%) & $44(11.9)$ & $370(97.4)$ \\
\hline $\begin{array}{l}\text { Estimated glomerular filtration } \\
\text { rate } \mathrm{mL} / \mathrm{min} / 1.73 \mathrm{~m}^{2} \text { mean (SD) }\end{array}$ & $57.4(19.9)$ & $375(98.7)$ \\
\hline $\begin{array}{l}\text { Haemoglobin A1c >6.9\% No. } \\
(\%)\end{array}$ & $27(8.9)$ & $304(80.0)$ \\
\hline Diseases No. (\%) & & $380(100)$ \\
\hline Neurological & $222(58.4)$ & \\
\hline Respiratory & $96(25.3)$ & \\
\hline
\end{tabular}

Continued
Table 1 Continued

\begin{tabular}{lrl}
\hline Variable & Results & $\begin{array}{l}\text { No. (\%) } \\
\text { tested }\end{array}$ \\
\hline Cardiac & $248(65.3)$ & \\
\hline Cancer & $47(12.9)$ & \\
\hline Osteoporotic fracture & $141(37.1)$ & \\
Osteoarthritis/chronic pain & $226(59.5)$ & \\
\hline Dementia diagnosis & $140(36.8)$ & \\
\hline Mood disorder & $187(49.2)$ & \\
\hline $\begin{array}{l}\text { Multiple (>2) comorbidities No. } \\
\text { (\%) }\end{array}$ & $324(85.3)$ & $380(100)$ \\
\hline Number of Drugs mean (SD) & $6.0(3.2)$ & $359(94.5)$ \\
\hline
\end{tabular}

$\mathrm{BP}$, blood pressure; SBP, systolic blood pressure.

(SD) age of the population was 88.4 (6.5), $72.4 \%$ were female and $41.2 \%$ lived in supportive housing. The mean CFS score was $5.6(0.8)$ with $60.5 \%$ being levels 6 to 7 (requiring assistance in BADL). The mean Gaitspeed was below $0.8 \mathrm{~m} / \mathrm{s}$, at $0.59(0.3)$ indicating this population was at higher risk of falling and death. The mean MNA-SF was 11.8 (2.1) with $5.2 \%$ scoring in the malnourished range $(<8)$ and $31.8 \%$ in the high risk (9 to 11$)$ range. Multiple comorbidities were found in $85.3 \%$ of people and a mean of 6.0 (3.2) drugs were prescribed.

We had complete follow-up data for all 380 people. The total observation period was 18 months, mean 10.0 (5.5) months. There were 39 (10.3\%) deaths, $48(12.6 \%)$ NHTs and $93(24.5 \%)$ discrete individuals admitted to hospital during the 18 months of follow-up.

The following variables were significantly associated with death (table 2 and online supplementary figures 1-6): CFS - HR 5.9 (95\% CI 3.1 to 11.2); EQ-5D - HR 6.3 (95\% CI 2.1 to 18.6); EQ-VAS - HR 7.0 (95\% CI 2.3 to 20.9); Gaitspeed - HR 5.9 (95\% CI 1.8 to 19.3); Gripstrength - HR 10.5 (95\% CI 3.7 to 30.3); MNA-SF - HR 8.4 (95\% CI 1.9 to 37.8 ); Hgb - HR 8.3 (95\% CI 3.1 to 22.3); eGFR - HR 5.7 (95\% CI 2.3 to 13.9); Cardiac Disease - HR 3.7 (95\% CI 1.9 to 7.1) and Cancer - HR 2.7 (95\% CI 1.0 to 7.1$)$.

Table 2 and online supplementary figures 1-6 show that NHT was significantly associated with: CFS - HR 6.0 (95\% CI 3.4 to 10.7); EQ-5D - HR 3.2 (95\% CI 1.3 to 7.8); EQ-VAS - 3.4 (95\% CI 1.2 to 9.4); Gaitspeed - HR 8.5 (95\% CI 3.2 to 22.8); Gripstrength - HR 10.6 (95\% CI 3.6 to 31.5 ); MNA-SF - HR 12.5 (CI could not be calculated because there were no events in the Q5 group); failed WST - HR 2.7 (95\% CI 1.0 to 7.4); MoCA - HR 4.6 (95\% CI 1.8 to 11.5 ) and GDS - HR 3.2 (95\% CI 1.6 to $6.7)$. None of the medical diagnoses or laboratory values besides Dementia - HR 5.7 (95\% CI 3.2 to 10.4) or Mood Disorder - HR 2.3 (95\% CI 1.3 to 4.0 ) was associated with increased risk of NHT.

Table 2 and online supplementary figures 1-6 show that HA was significantly associated with: CFS - HR 2.9 


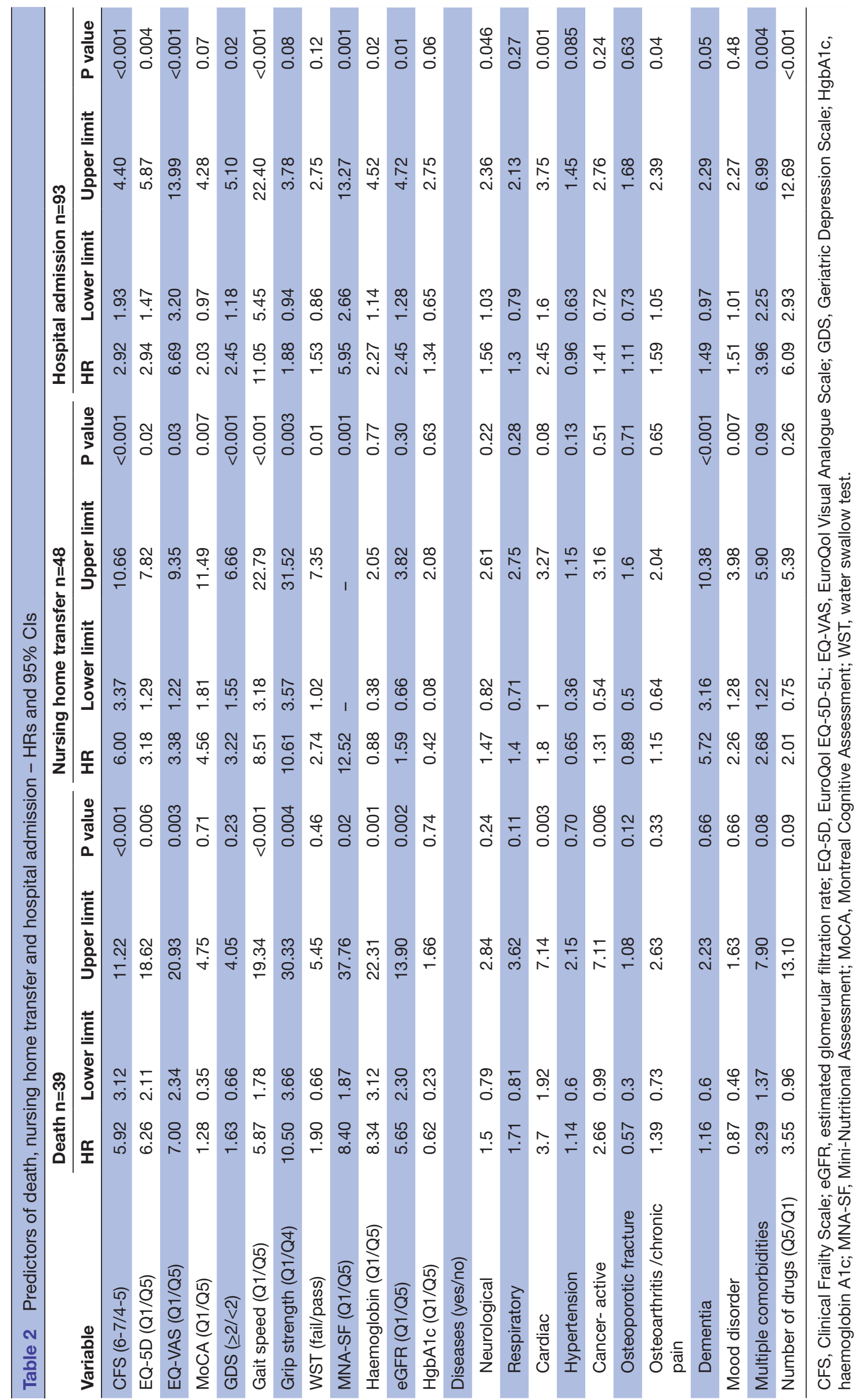




\begin{tabular}{|c|c|c|c|c|}
\hline Variable & $\begin{array}{l}\text { Unadjusted HR } \\
(95 \% \mathrm{Cl})\end{array}$ & $P$ value & $\begin{array}{l}\text { Adjusted HR* } \\
(95 \% \mathrm{Cl})\end{array}$ & $P$ value \\
\hline Death & & & & $(<0.001) \dagger$ \\
\hline Clinical frailty scale & $3.50(2.15$ to 5.71$)$ & $<0.001$ & 2.88 (1.23 to 6.68$)$ & 0.014 \\
\hline EuroQol-VAS & 0.96 (0.95 to 0.98$)$ & $<0.001$ & 0.96 (0.93 to 0.98$)$ & $<0.001$ \\
\hline eGFR & 0.96 (0.95 to 0.98$)$ & $<0.001$ & 0.97 (0.95 to 1.00$)$ & 0.04 \\
\hline Haemoglobin & 0.97 (0.95 to 0.99$)$ & $<0.001$ & 0.97 (0.94 to 0.99$)$ & 0.02 \\
\hline Nursing home transfer & & & & $(<0.001) \dagger$ \\
\hline Age & 1.07 (1.01 to 1.12$)$ & $<0.01$ & $1.10(1.02$ to 1.18$)$ & 0.02 \\
\hline Gait speed & 0.10 (0.03 to 0.31$)$ & $<0.001$ & 0.13 (0.03 to 0.57$)$ & 0.01 \\
\hline Geriatric depression scale & 1.55 (1.25 to 1.91$)$ & $<0.001$ & 1.39 (1.07 to 1.82$)$ & 0.01 \\
\hline Dementia diagnosis & 5.75 (2.99 to 11.06$)$ & $<0.001$ & 4.61 (1.86 to 11.44$)$ & 0.001 \\
\hline Hospital admission & & & & $(<0.001) \dagger$ \\
\hline Clinical frailty scale & 2.04 (1.54 to 2.71$)$ & $<0.001$ & 1.75 (1.21 to 2.51$)$ & 0.003 \\
\hline EuroQol-VAS & 0.97 (0.96 to 0.99$)$ & $<0.001$ & 0.98 (0.96 to 0.99$)$ & 0.004 \\
\hline
\end{tabular}

${ }^{*}$ Adjusted for age, sex, multiple comorbidities, number of drugs and variables in final model. †P for overall model.

eGFR, estimated glomerular filtration rate; VAS, Visual Analogue Scale.

(95\% CI 1.9 to 4.4); EQ-5D - HR 2.9 (95\% CI 1.5 to 5.9 ); EQ-VAS - HR 6.7 (95\% CI 3.2 to 14.0); GDS - HR 2.5 (95\% CI 1.2 to 5.1); Gaitspeed - HR 11.1 (95\% CI 5.5 to 22.4 ); Hgb - HR 2.3 (95\% CI 1.1 to 4.5); eGFR - HR 2.5 (95\% CI 1.3 to 4.7 ); Cardiac Disease - HR 2.5 (95\% CI 1.6 to 3.8); Osteoarthritis/Chronic pain - HR 1.6 (95\% CI 1.1 to 2.4), Multiple Comorbidities - HR 4.0 (95\% CI 2.3 to 7.0) and the Number of Drugs - HR 6.1 (95\% CI 2.9 to 12.7).

Multivariate analysis using Cox proportional hazards model was used to calculate adjusted HR (aHR) (table 3). Death was independently associated with: CFS (aHR 2.88, $95 \%$ CI 1.23 to 6.68 ); EQ-VAS (aHR 0.96, $95 \%$ CI 0.93 to 0.98); eGFR (aHR $0.97,95 \%$ CI 0.95 to 1.00 ) and $\mathrm{Hgb}$ (aHR $0.97,95 \%$ CI 0.94 to 0.99 ). The $\mathrm{p}$ value for the model was $<0.001$. NHT was independently associated with: Gaitspeed (aHR 0.13, 95\% CI 0.03 to 0.57); GDS (aHR 1.39, 95\% CI 1.07 to 1.82) and Dementia (aHR 4.61, $95 \%$ CI 1.86 to 11.44 ). CFS was not statistically significant in this model when gait speed was added. The $p$ value for the overall model was $<0.001$. HA was associated with CFS (aHR 1.75, 95\% CI 1.21 to 2.51); EQ-VAS (aHR 0.98, $95 \%$ CI 0.96 to 0.99 ). The $p$ value for the overall model was $<0.001$. No other diagnoses, multiple comorbidities, other frailty measures or number of drugs were significant in any of these models.

Table 4 shows that that CFS level predicted abnormal health status measures. All the frailty and health status measures were significantly worse for CFS levels 5 to 7 compared with CFS level 2 to 4.

Online supplementary table 1 compares the characteristics and outcomes for respondents and non-respondents. The $53(13.9 \%)$ non-respondents were significantly more frail (mean CFS $6.0 \pm 0.8$ vs $5.5 \pm 0.8$ ) and were more likely to have a dementia diagnoses compared with respondents $(\mathrm{n}=31(58.5 \%)$ vs $109(33.3 \%))$. All three outcomes were more common in the non-respondents. Online supplementary table 2 show that there was no appreciable difference in the HRs, CIs or $\mathrm{p}$ values for two representative

Table 4 Comparison of test scores by clinical frailty scale (CFS) level

\begin{tabular}{lccl}
\hline Variable & $\begin{array}{l}\text { CFS 2-4 } \\
\mathbf{n = 3 8}\end{array}$ & $\begin{array}{l}\text { CFS 5-7 } \\
\mathbf{n = 3 4 2}\end{array}$ & P value \\
\hline EuroQol EQ-5D-5L mean (SD) & $0.84(0.11)$ & $0.71(0.18)$ & $<0.001$ \\
\hline EuroQol visual analogue scale mean (SD) & $82.09(14.03)$ & $70.22(18.74)$ & $<0.001$ \\
Gait speed mean (SD) & $0.92(0.29)$ & $0.54(0.28)$ & $<0.001$ \\
Grip strength mean (SD) & $23.54(10.05)$ & $15.21(15.89)$ & 0.002 \\
Mini-nutritional assessment short form mean (SD) & $12.78(1.44)$ & $11.67(2.08)$ & 0.002 \\
Montreal cognitive assessment mean (SD) & $26.00(3.23)$ & $19.84(6.32)$ & $<0.001$ \\
5-point geriatric depression scale mean (SD) & $0.56(0.88)$ & $1.40(1.36)$ & $<0.001$ \\
Water swallow test - failure No. (\%) & $3(8.3 \%)$ & $64(23.6 \%)$ & $\mathrm{p}=0.05$ \\
\hline
\end{tabular}


variables (EQ-5D and Gaitspeed) when imputed values were used for the survival analyses.

\section{DISCUSSION}

This study demonstrates that for an elderly population, simple tests for general frailty (CFS), physical health (Gaitspeed and MNA-SF) and HRQoL/self-reported general health (EQ-5D and EQ-VAS) strongly predicted the risk of death, NHT and HA. Additionally, measures of cognitive impairment (MoCA), mood (GDS) and dysphagia (WST) and Gripstrength predicted the risk of NHT and GDS predicted HA. Polypharmacy (number of drugs) and multiple comorbidities, both considered geriatric risk markers, predicted HA but not death nor NHT.

The frailty measures appeared to be stronger predictors of death than chronic disease diagnoses. These findings are consistent with other studies examining the relationship between functional decline, chronic diseases, health outcomes $^{43}$ and mortality. ${ }^{44}$ For traditional medical diagnostic categories, cardiac disease and cancer were more weakly associated with death compared with frailty measures. Dementia and mood disorder predicted NHT. Cardiac disease and osteoarthritis/chronic pain weakly predicted HA. Low eGFR and Hgb were exceptions and strongly predicted death and less strongly predicted HA.

Kaplan-Meier curves (online supplementary figures 1-6) demonstrate that the high and low risk groups separate from each other early and that HRs are both clinically and statistically significant within 12 months. For example, these curves showed that the median survival for CFS Level 7 was 13 months (online supplementary figure 4 ), which is similar to stage 4 lung cancer ${ }^{45}$ and significantly lower than for people with metastatic breast ${ }^{46}$ or prostate cancer. ${ }^{47}$ Therefore, prognostic information from these tests may be extremely valuable for patients and families deciding about the intensity of medical interventions that they want, as well as the need for community and institutional supports. These findings also show that frailty is not an 'all or none' risk phenomena but exists along a continuum.

There is overlap in what these tests measure which includes: function and symptoms (CFS/EQ-5D); physical problems (EQ-5D, MNA-SF, Gaitspeed and Gripstrength) and mental health problems (EQ-5D, GDS, MoCA and MNA-SF). It is tempting to rely on one measure such as the CFS which simply classifies frailty and strongly predicted adverse outcomes. However, it does not tell us about an individual's mood, cognitive function, strength, gait and balance, HRQoL, chronic symptoms, swallowing problems or nutritional risk. In addition to measuring unique dimensions of health status, these tests may change over time and be modifiable risk markers. While it is unusual for people with chronic frailty to improve to a better CFS level, there is evidence that EQ-5D, EQ-VAS, Gaitspeed, Gripstrength, MNA-SF, GDS and MoCA may be modifiable and that improvements in scores may lower peoples' risk for adverse outcomes. ${ }^{32} 33$ 48-52 Each of these tests is responsive to change in health and have minimally clinical important differences established, ${ }^{51}{ }^{53-60}$. Therefore, repeating these tests may be useful to assess interventions (eg, a medication change or rehabilitation treatment) for individual patients as well as to evaluate aggregated changes for a programme. We are planning to use this data to evaluate our interdisciplinary team interventions for individuals and to aggregate the before/after data to evaluate our programme.

Reduced HRQoL at baseline, as measured by the EQ-5D, was shown to be a strong risk factor for adverse outcomes. These findings are consistent with other studies for general ${ }^{61}$ and elderly populations. ${ }^{62} \mathrm{HRQOL}$ is arguably not only a risk factor, but one of the most important outcome measures and goals of care for elderly people. The EQ-5D is the only test that may be complex to use and interpret. It requires the use of population norms and conversion into a summary index which can be loosely interpreted as an assessment of how people value their current health status. ${ }^{21}$ The EQ-VAS, which uses a 100-point vertical visual analogue scale for general health was a very simple test and strong predictor for all outcomes. The scores for the EQ-VAS and EQ-5D were remarkably similar in our study with a correlation coefficient of $0.48 p<0.001$. Therefore, it may be possible to use the EQ-VAS as a proxy measure for HRQoL when software or population norms for the EQ-5D are not readily available. We were able to benchmark our population and show that when HRQoL as measured by EQ-5D and EQ-VAS drops below 0.7/70 (Quintile 1), risk for death, NHT and HA significantly increased.

These tests were administered by a trained nurse, but all or parts of the FACTS assessment could easily be administered by any trained team member. The cost of administering the complete assessment was 1 hour of nursing time. This is less costly than a typical battery of blood tests or scans done for a geriatric assessment. Most of the individual tests took less that 5 to $10 \mathrm{~min}$ to administer.

The results from the bivariate analyses show that not all elderly people need to have a complete FACTS assessment. The mean test values were largely in the normal range for CFS $<5$. Therefore, well elderly people could initially be screened with the CFS and if the level is $\geq 5$, more complete testing could be done.

\section{Strengths and limitations}

The strengths of this study are the inclusion of a large number of very old and frail people, high test administration rates and complete follow-up of outcomes. The pragmatic nature of this study of 'usual care' with assessments done by the practice nurses adds to its generalisability. The tests used have been well studied and shown to be valid, reliable and responsive across populations, for different diseases and in different clinical settings ${ }^{32} 38495263-72$. The unique aspect of this study is using these health status tests to measure multiple domains of health, including HRQoL in a primary care setting and aggregating the results to predict adverse outcomes. There was a relatively 
low non-response rate to the frailty tests confirming that this assessment is well tolerated and acceptable to most frail elderly people in a practice setting.

Non-responders were slightly frailer on the CFS, more likely to have dementia and had higher rates of the three outcomes. However, analysis with imputed values for missing data did not diminish the strength of the HRs or statistical significance, indicating there was not a response-rate bias compromising the results.

The limitations of this study are that the results, including absolute risks and time-to-event may not be generalisable to 'younger elderly' groups or non-elderly populations with disabilities. Similarly, we cannot generalise these results to a non-frail elderly population or frail people living in nursing homes or being treated in hospitals. This study only involved one practice. Further testing would need to be done to scale and generalise this model of assessment for epidemiological tracking and programme evaluation for larger healthcare populations (eg, an health maintenance organisation, regional family medicine network or geriatric consulting programme). We did not control for socioeconomic status and social risk factors because our population largely came from homogeneous middle and upper-middle class backgrounds. We also had very low completion rates for questionnaires pertaining to caregiver burden, so we were unable to examine this risk factor as part of this study. The small number of values in the subgroups may have led to Type 2 Errors. It is possible that the lack of association with multiple comorbidities was due to the high frequency of disease in this population and an inadequate number of internal controls. There were multiple comparisons in this study, but the key results were highly significant and consistent, making it unlikely the findings were due to random error.

It is possible that there was measurement bias because practice nurses who knew the patients performed the assessments. However, the nurses did not record outcomes and the prospective design limited this possibility.

\section{CONCLUSIONS}

For an elderly population, simple measures of physical health, mental health, HRQoL and general frailty, administered as part of usual medical care are stronger predictors of mortality, NHT and HA than traditional medical diagnoses. Consideration should be given to incorporating these measures into routine medical care.

Acknowledgements Elizabeth Zacharias MSc for assisting with the audit and reviewing the manuscript. Dr Margaret McGregor, Head Community Geriatrics, Department of Family Practice University of British Columbia, for supporting this research with a financial grant. Joyce Constantine - Island Health Library Services for assisting with the literature review. Dr Jonathan Berkowitz for his statistical consultation.

Contributors TR conceived the host study. TR, PM, VH and RL planned the study and protocol. VH planned the test administration, trained nurses and was involved in the data collection. TR, VH and RL planned the data management and abstraction. TR performed the statistical analyses. TR and PM conceived the manuscript idea, drafted the manuscript and revised the manuscript for content. All authors reviewed the final manuscript and have contributed significantly to the work presented within this manuscript have been listed above.

Funding The FACTS study was supported with a grant from the section of Community Geriatrics, Department of Family Practice, University of British Columbia.

Competing interests None declared.

Patient consent for publication Not required.

Ethics approval This study was approved by the University of British Columbia Clinical Research Ethics Board (H15-03528).

Provenance and peer review Not commissioned; externally peer reviewed.

Data availability statement Data are available upon reasonable request.

Open access This is an open access article distributed in accordance with the Creative Commons Attribution Non Commercial (CC BY-NC 4.0) license, which permits others to distribute, remix, adapt, build upon this work non-commercially, and license their derivative works on different terms, provided the original work is properly cited, appropriate credit is given, any changes made indicated, and the use is non-commercial. See: http://creativecommons.org/licenses/by-nc/4.0/.

ORCID iD

Ted Rosenberg http://orcid.org/0000-0001-7191-8036

\section{REFERENCES}

$1 \mathrm{CIHI}$, QuickStats. Inpatient hospitalizations: volumes, length of stay, and standardized rates: 2048001, 2016. Available: https://apps. cihi.ca/mstrapp/asp/Main.aspx?Server=apmstrextprd_i\&project= Quick Stats\&uid=pce_pub_en\&pwd=\&evt $=2048001 \&$ visualization Mode=0\&documentID=C6F8B4144B03958E3AE3CAB5DD440EA7

$2 \mathrm{CIHI}$. Profile of residents in residential and hospital-based continuing care 2017-2018. Available: https://www.cihi.ca/

3 Clegg A, Young J, Iliffe S, et al. Frailty in elderly people. Lancet 2013;381:752-62.

4 Song X, Mitnitski A, Rockwood K. Prevalence and 10-year outcomes of frailty in older adults in relation to deficit accumulation. J Am Geriatr Soc 2010;58:681-7.

5 Wachterman MW, Pilver C, Smith D, et al. Quality of end-of-life care provided to patients with different serious illnesses. JAMA Intern Med 2016;176:1095-105.

6 Kojima G. Frailty as a predictor of hospitalisation among communitydwelling older people: a systematic review and meta-analysis. $J$ Epidemiol Community Health 2016;70:722-9.

7 Kojima G. Frailty as a predictor of disabilities among communitydwelling older people: a systematic review and meta-analysis. Disabil Rehabil 2017;39:1897-908.

8 Kojima G. Frailty as a predictor of nursing home placement among community-dwelling older adults: a systematic review and metaanalysis. J Geriatr Phys Ther 2018;41:42-8.

9 Gale CR, Cooper C, Sayer AA. Prevalence of frailty and disability: findings from the English longitudinal study of ageing. Age Ageing 2015;44:162-5

10 Santos-Eggimann B, Cuénoud P, Spagnoli J, et al. Prevalence of frailty in middle-aged and older community-dwelling Europeans living in 10 countries. J Gerontol A Biol Sci Med Sci 2009;64:675-81.

11 Collard RM, Boter H, Schoevers RA, et al. Prevalence of frailty in community-dwelling older persons: a systematic review. J Am Geriatr Soc 2012;60:1487-92.

12 Reeves D, Pye S, Ashcroft DM, et al. The challenge of ageing populations and patient frailty: can primary care adapt? BMJ 2018;362:k3349-7.

13 Clegg A, Rogers L, Young J. Diagnostic test accuracy of simple instruments for identifying frailty in community-dwelling older people: a systematic review. Age Ageing 2015;44:148-52.

14 Rockwood K, Song X, MacKnight C, et al. A global clinical measure of fitness and frailty in elderly people. CMAJ 2005;173:489-95.

15 Theou O, Brothers TD, Peña FG, et al. Identifying common characteristics of frailty across seven scales. J Am Geriatr Soc 2014;62:901-6.

16 Jia H, Lubetkin El, DeMichele K, et al. Comparing the performance of 2 health utility measures in the Medicare health outcome survey (HOS). Med Decis Making 2018;38:983-93.

17 De Buyser SL, Petrovic M, Taes YE, et al. A multicomponent approach to identify predictors of hospital outcomes in older in-patients: a multicentre, observational study. PLoS One 2014;9:e115413. 
18 Lilamand M, Kelaiditi E, Demougeot L, et al. The mini nutritional assessment-short form and mortality in nursing home residents results from the INCUR study. J Nutr Health Aging 2015;19:383-8.

19 Rosenberg T, Lattimer R, Hay V, et al. •Comparison of 3 meter and 4 meter gait speed in a home setting for a frail population. J Am Geriatr Soc 2016;64:S53-4

20 Rosenberg T. Acute hospital use, nursing home placement, and mortality in a frail community-dwelling cohort managed with primary integrated interdisciplinary elder care at home. J Am Geriatr Soc 2012;60:1340-6.

21 Xie F, Pullenayegum E, Gaebel K, et al. A time Trade-off-derived value set of the EQ-5D-5L for Canada. Med Care 2016;54:98-105.

22 Hoyl MT, Alessi CA, Harker JO, et al. Development and testing of a five-item version of the geriatric depression scale. J Am Geriatr Soc 1999;47:873-8.

23 Rinaldi P, Mecocci P, Benedetti C, et al. Validation of the five-item geriatric depression scale in elderly subjects in three different settings. J Am Geriatr Soc 2003;51:694-8.

24 Nguyen HV, Inderjeeth CA, Tang E, et al. Screening for depression in hospitalised and community-dwelling elderly: the use of the 4-item, 5-item and 15-item geriatric depression scales. Australas J Ageing 2006;25:204-8.

25 Rubenstein LZ, Harker JO, Salvà A, et al. Screening for undernutrition in geriatric practice: developing the short-form mininutritional assessment (MNA-SF). J Gerontol A Biol Sci Med Sci 2001;56:M366-72.

26 Helminen H, Luukkaala T, Saarnio J, et al. Comparison of the Mini-Nutritional assessment short and long form and serum albumin as prognostic indicators of hip fracture outcomes. Injury 2017;48:903-8.

27 Donini LM, Poggiogalle E, Molfino A, et al. Mini-Nutritional assessment, malnutrition universal screening tool, and nutrition risk screening tool for the nutritional evaluation of older nursing home residents. J Am Med Dir Assoc 2016;17:959.e11-8.

28 Shakersain B, Santoni G, Faxén-Irving G, et al. Nutritional status and survival among old adults: an 11-year population-based longitudinal study. Eur J Clin Nutr 2016;70:320-5.

29 Studenski S, Perera S, Patel K, et al. Gait speed and survival in older adults. JAMA 2011;305:50-8.

30 Bohannon RW. Measurement of gait speed of older adults is feasible and informative in a home-care setting. J Geriatr Phys Ther 2009;32:22-3.

31 Peel NM, Kuys SS, Klein K. Gait speed as a measure in geriatric assessment in clinical settings: a systematic review. J Gerontol $A$ Biol Sci Med Sci 2013;68:39-46.

32 Celis-Morales CA, Welsh P, Lyall DM, et al. Associations of grip strength with cardiovascular, respiratory, and cancer outcomes and all cause mortality: prospective cohort study of half a million UK Biobank participants. BMJ 2018;361:k1651.

33 Leong DP, Teo KK, Rangarajan S, et al. Prognostic value of grip strength: findings from the prospective urban rural epidemiology (pure) study. Lancet 2015;386:266-73.

34 Alley DE, Shardell MD, Peters KW, et al. Grip strength cutpoints for the identification of clinically relevant weakness. J Gerontol A Biol Sci Med Sci 2014;69:559-66.

35 Depippo KL, Holas MA, Reding MJ, et al. Validation of the 3-Oz water swallow test for aspiration following stroke. Available: www. archneurol.com

36 González-Fernández M, Humbert I, Winegrad H, et al. Dysphagia in old-old women: prevalence as determined according to selfreport and the 3-ounce water swallowing test. J Am Geriatr Soc 2014;62:716-20.

37 Wu M-C, Chang Y-C, Wang T-G, et al. Evaluating swallowing dysfunction using a $100-\mathrm{ml}$ water swallowing test. Dysphagia 2004;19:43-7.

38 Suiter DM, Leder SB. Clinical utility of the 3-ounce water swallow test. Dysphagia 2008;23:244-50.

39 Nogueira D, Reis E. Swallowing disorders in nursing home residents: how can the problem be explained? Clin Interv Aging 2013;8:221-7.

40 Garon BR, Engle M, Ormiston C. Reliability of the 3-Oz water swallow test utilizing cough reflex as sole indicator of aspiration. Neurorehabil Neural Repair 1995

41 Leder SB, Suiter DM, Green BG. Silent aspiration risk is volumedependent. Dysphagia 2011;26:304-9.

42 American Geriatrics Society Expert Panel on the Care of Older Adults with Multimorbidity. Patient-centered care for older adults with multiple chronic conditions: a stepwise approach from the American geriatrics Society: American geriatrics Society expert panel on the care of older adults with multimorbidity. J Am Geriatr Soc 2012;60:1957-68.
43 Denti L, Artoni A, Casella M, et al. Validity of the modified Charlson comorbidity index as predictor of short-term outcome in older stroke patients. J Stroke Cerebrovasc Dis 2015;24:330-6.

44 Formiga F, Ferrer A, Padros $\mathrm{G}$, et al. Evidence of functional declining and global comorbidity measured at baseline proved to be the strongest predictors for long-term death in elderly community residents aged 85 years: a 5-year follow-up evaluation, the OCTABAIX study. Clin Interv Aging 2016;11:437-44.

45 Carbone DP, Reck M, Paz-Ares L, et al. First-Line nivolumab in stage IV or recurrent non-small-cell lung cancer. $N$ Engl J Med 2017;376:2415-26.

46 Mehta RS, Barlow WE, Albain KS, et al. Overall survival with fulvestrant plus anastrozole in metastatic breast cancer. $N$ Engl $J$ Med 2019;380:1226-34.

47 Sweeney CJ, Chen Y-H, Carducci M, et al. Chemohormonal therapy in metastatic hormone-sensitive prostate cancer. $N$ Engl J Med 2015;373:737-46.

48 Van Abbema R, De Greef M, Crajé C, et al. What type, or combination of exercise can improve preferred gait speed in older adults? A meta-analysis. BMC Geriatr 2015;15

49 Ostir G, Berges I. Gait speed in older patients admitted to an acute care for elders Hospital unit. J Am Geriatr Soc 2012;60.

50 Roberts HC, Syddall HE, Cooper C, et al. Is grip strength associated with length of stay in hospitalised older patients admitted for rehabilitation? findings from the Southampton grip strength study. Age Ageing 2012;41:641-6.

51 Zanini A, Aiello M, Adamo D, et al. Estimation of minimal clinically important difference in EQ-5D visual analog scale score after pulmonary rehabilitation in subjects with COPD. Respir Care 2015;60:88-95.

52 Abizanda P, López MD, García VP, et al. Effects of an oral nutritional supplementation plus physical exercise intervention on the physical function, nutritional status, and quality of life in frail institutionalized older adults: the ACTIVNES study. J Am Med Dir Assoc 2015;16:439. e9-16.

53 Bohannon RW. Minimal clinically important difference for grip strength: a systematic review. J Phys Ther Sci 2019;31:75-8.

54 Bilbao A, García-Pérez L, Arenaza JC, et al. Psychometric properties of the EQ-5D-5L in patients with hip or knee osteoarthritis: reliability, validity and responsiveness. Qual Life Res 2018;27:2897-908.

55 Chen P, Lin K-C, Liing R-J, et al. Validity, responsiveness, and minimal clinically important difference of EQ-5D-5L in stroke patients undergoing rehabilitation. Qual Life Res 2016;25:1585-96.

56 Bohannon RW, Glenney SS. Minimal clinically important difference for change in comfortable gait speed of adults with pathology: a systematic review. J Eval Clin Pract 2014;20:295-300.

57 Wu C-Y, Hung S-J, Lin K-C, et al. Responsiveness, minimal clinically important difference, and validity of the MoCA in stroke rehabilitation. Occup Ther Int 2019;2019:2517658.

58 Lang CE, Edwards DF, Birkenmeier RL, et al. Estimating minimal clinically important differences of upper-extremity measures early after stroke. Arch Phys Med Rehabil 2008;89:1693-700.

59 Lim PA, McLean AM, Kilpatrick C, et al. Temporal stability and responsiveness of the Montreal cognitive assessment following acquired brain injury. Brain Inj 2016;30:29-35.

60 Costa AS, Reich A, Fimm B, et al. Evidence of the sensitivity of the MoCA alternate forms in monitoring cognitive change in early Alzheimer's disease. Dement Geriatr Cogn Disord 2014;37:95-103.

61 Jerant A, Tancredi DJ, Franks P. Mortality prediction by qualityadjusted life year compatible health measures: findings in a nationally representative US sample. Med Care 2011;49:443-50.

62 Cavrini G, Broccoli S, Puccini A, et al. EQ-5D as a predictor of mortality and hospitalization in elderly people. Qual Life Res 2012;21:269-80.

63 Sexton DJ, Lowney AC, O'Seaghdha CM, et al. Do patient-reported measures of symptoms and health status predict mortality in hemodialysis? an assessment of POS-S renal and EQ-5D. Hemodial Int 2016;20:618-30.

64 Ambrosy AP, Hernandez AF, Armstrong PW, et al. The clinical course of health status and association with outcomes in patients hospitalized for heart failure: insights from ASCEND-HF. Eur $J$ Heart Fail 2016;18:306-13.

65 McEwen LN, Kim C, Haan MN, et al. Are health-related qualityof-life and self-rated health associated with mortality? insights from translating research into action for diabetes (triad). Prim Care Diabetes 2009;3:37-42.

66 Clarke PM, Hayes AJ, Glasziou PG, et al. Using the EQ-5D index score as a predictor of outcomes in patients with type 2 diabetes. Med Care 2009;47:61-8. 
67 Issa SM, Hoeks SE, Scholte op Reimer WJM, et al. Health-related quality of life predicts long-term survival in patients with peripheral artery disease. Vasc Med 2010;15:163-9.

68 Ayis S, Wellwood I, Rudd AG, et al. Variations in health-related quality of life (HRQoL) and survival 1 year after stroke: five European population-based registers. BMJ Open 2015;5:e007101.

69 Parlevliet JL, MacNeil-Vroomen J, Buurman BM, et al. Health-related quality of life at admission is associated with Postdischarge mortality, functional decline, and institutionalization in acutely hospitalized older medical patients. J Am Geriatr Soc 2016;64:761-8.
70 Liu G-X, Chen Y, Yang Y-X, et al. Pilot study of the Mini Nutritional Assessment on predicting outcomes in older adults with type 2 diabetes. Geriatr Gerontol Int 2017;17:2485-92.

71 Chu C-S, Liang C-K, Chou M-Y, et al. Mini-nutritional assessment short-form as a useful method of predicting poor 1-year outcome in elderly patients undergoing orthopedic surgery. Geriatr Gerontol Int 2017;17:2361-8.

72 Hunger M, Sabariego C, Stollenwerk B, et al. Validity, reliability and responsiveness of the EQ-5D in German stroke patients undergoing rehabilitation. Qual Life Res 2012;21:1205-16. 